\title{
OPEN
}

\section{Author Correction: TGF- $\beta 1$-induced HSP47 regulates extracellular matrix accumulation via Smad2/3 signaling pathways in nasal fibroblasts}

Hae-Ji Kim, Joo-Hoo Park $\mathbb{D}$, Jae-Min Shin, Hyun-Woo Yang, Heung-Man Lee \& II-Ho Park (D)

Correction to: Scientific Reports https://doi.org/10.1038/s41598-019-52064-1, published online 29 October 2019

This Article contains errors.

As a result of an error during figure assembly, some of the HSP47/DAPI images in Figure 2F duplicate HSP47/

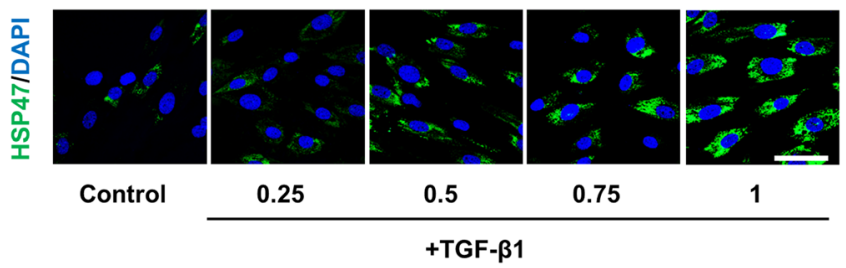

Figure 1.

DAPI images in Figure 3C. Specifically, the control image in Figure 2F duplicates the first HSP47/DAPI image in Figure $3 \mathrm{C}$, the $0.25+$ TGF- $\beta 1$ image in Figure $2 \mathrm{~F}$ duplicates the third HSP47/DAPI image in Figure 3C, and the $0.75+$ TGF- $\beta 1$ image in Figure 2F duplicates the second HSP47/DAPI image in Figure 3C. The correct Figure $2 \mathrm{~F}$ is shown below as Figure 1 .

Original data for the Western blots shown in the main figures was not included in the Article. It is now included in the Supplementary Information file attached below.

These corrections do not affect the overall conclusions of the Article.

\section{Additional information}

Supplementary information is available for this paper at https://doi.org/10.1038/s41598-020-66547-z.

(c) (i) Open Access This article is licensed under a Creative Commons Attribution 4.0 International License, which permits use, sharing, adaptation, distribution and reproduction in any medium or format, as long as you give appropriate credit to the original author(s) and the source, provide a link to the Creative Commons license, and indicate if changes were made. The images or other third party material in this article are included in the article's Creative Commons license, unless indicated otherwise in a credit line to the material. If material is not included in the article's Creative Commons license and your intended use is not permitted by statutory regulation or exceeds the permitted use, you will need to obtain permission directly from the copyright holder. To view a copy of this license, visit http://creativecommons.org/licenses/by/4.0/. 